\title{
Relatively stable carbon stocks in China's grasslands
}

\author{
FANG ChangMing \\ Ministry of Education Key Laboratory for Biodiversity and Ecological Engineering, Fudan University, Shanghai 200433, China
}

Received March 2, 2011; accepted March 07, 2011

Citation: $\quad$ Fang C M. Relatively stable carbon stocks in China's grasslands. Sci China Life Sci, 2011, 54: 490-492, doi: 10.1007/s11427-011-4169-7

Global climate change has been predicted to profoundly influence carbon (C) processes and $\mathrm{C}$ stock dynamics in terrestrial ecosystems [1]. Three papers recently published in Science China Life Science [2-4] studied various aspects of $\mathrm{C}$ stock dynamics at different scales in the northern grasslands of China (including the Tibetan alpine meadow). They reported that there has been no significant trend of variation in ecosystem $\mathrm{C}$ stocks in Tibetan meadow and temperate grassland since the late 1980 s, or significant correlation between variations in $\mathrm{C}$ stocks and warming or precipitation. The response of ecosystem $\mathrm{C}$ processes and $\mathrm{C}$ stocks to global climate change featuring a significant temperature rise was insignificant.

At the level of an individual plant, Wang et al. [2] revealed that the ratio of below- to above-ground biomass of herbaceous species $(R / S)$ in northern China varied between 0.2 and 17.7 , with a median of 0.78 . The slope of the allometric relationship between above- and below-ground biomass in China's grassland was smaller than that a global scale, and was significantly steeper in the temperate grassland than in the Tibetan alpine meadow. The spatial variation in $R / S$ in China's grasslands was not significantly correlated with mean annual temperature or mean annual precipitation. The biomass distribution did not support the hypothesis of isometric growth between below- and above-ground biomass.

Based on field data from 341 sites and normalized difference vegetation index (NDVI) data over the period of 1982-2006 in northern China's grasslands, Ma et al. [3]

email: cmfang@fudan.edu.cn found that grassland biomass had not significantly changed since the late 1980s, though a weak increase in biomass in northern China's grassland over the period of 1982-2006, with an average increase rate of $0.2 \mathrm{Tg} \mathrm{C} \mathrm{yr}^{-1}$, has been observed. The total biomass $\mathrm{C}$ in northern China's grasslands was estimated at $557.5 \mathrm{Tg} \mathrm{C}$, of which $86 \%$ in below-ground. The interannual variation in biomass $\mathrm{C}$ stocks in grasslands was mainly influenced by precipitation during the growing season (from January to July), and also weakly affected by temperature during this period. More specifically, variations in biomass $\mathrm{C}$ in the arid grasslands of the desert and typical steppes were significantly correlated with precipitation, while biomass $\mathrm{C}$ in the alpine meadow was positively correlated with the mean temperature from January to July.

Fang et al. [4] combined datasets from previous studies $[5,6]$ to compare the findings of different studies conducted across China over last two decades. They showed that the estimate of biomass $\mathrm{C}$ density (C stock per area) of China's grasslands made by different studies greatly varied, with a range of 215.8-348.1 $\mathrm{g} \mathrm{C} \mathrm{m}^{-2}$ and an average of $300.2 \mathrm{~g} \mathrm{C} \mathrm{m}^{-2}$, and that soil organic $\mathrm{C}$ density had a range of $8.5-15.1 \mathrm{~kg} \mathrm{C} \mathrm{m}^{-2}$. In total, ecosystem $\mathrm{C}$ stock in China's grassland was estimated at 29.1 $\mathrm{Pg} \mathrm{C}$, based on the mean soil organic $\mathrm{C}$ density of $8.5 \mathrm{~kg} \mathrm{C} \mathrm{m}^{-2}$ of field data from approximately 1000 soil profiles across the country and China's grassland area $\left(331 \times 10^{4} \mathrm{~km}^{2}\right)$. Neither biomass nor soil organic $\mathrm{C}$ stock in China's grasslands showed a significant change during last 20 years, suggesting a neutral $\mathrm{C}$ response in grassland ecosystems to global climate change.

These three papers revealed that the productivity and $\mathrm{C}$ 
stocks in northern China's grasslands, either at the individual, community or regional scale, did not respond significantly to climate change during the last two decades, though a weak $\mathrm{C}$ sink was estimated.

The $\mathrm{C}$ cycle of ecosystems is featured by $\mathrm{C}$ input as the net productivity, $\mathrm{C}$ output as the total respiration and $\mathrm{C}$ stocks in ecosystems. In grassland ecosystems, the $\mathrm{C}$ output from ecosystems is mainly the respiration from the soil. Soil respiration has been stimulated by global climate change in last few decades, with a corresponding $Q_{10}$ value of 1.5 [7], suggesting that warming has increased the $\mathrm{C}$ output from ecosystems. The changes in net productivity and respiration of ecosystems in high latitude regions have been suggested to be greater than those in low latitude regions because the former experiences a higher temperature increase. The below-ground biomass in perennial grasslands reflects the accumulation of ecosystem production over few years. However, the above-ground biomass in these ecosystems is mainly related to the annual net productivity of the ecosystem and thus interannual variation in the above-ground biomass reflects interannual variation in net productivity. The lack of variation in the above-ground biomass and soil organic C stocks in northern China's grasslands over the last two decades suggests there has been no significant change in soil respiration, or the decomposition of soil organic $\mathrm{C}$, in respect to climate change of the period. This conflicts with the findings of studies making short-term field observations or performing small-scale experiments. The variation in above-ground biomass in the Inner Mongolia grassland was reported to be mainly controlled by the interaction between temperature and precipitation during the growing season. Over last two decades, the biomass of the grassland at the beginning of the growing season (May) has increased by $21.8 \%$, but decreased by $29.7 \%$ at the end of the growing season (Sept). Experimental warming alone has decreased the net productivity, while warming in combination with increased precipitation has enhanced the net productivity of these ecosystems [8,9]. In semi-arid grasslands of northern China, the reduction in soil respiration caused by the variation in annual precipitation, due to global warming over the past decades, was unlikely to fully counteract the positive effects of increased temperature. In the Tibetan alpine meadow, soil respiration is commonly inhibited by high soil moisture, which means that a reduction in precipitation should stimulate not decrease soil respiration. The mechanisms underlying the relatively stable $\mathrm{C}$ stocks, $\mathrm{C}$ input and output in northern China's grasslands, especially those causing the different responses of soil respiration to short-term environment fluctuation and long-term climate change, remain unclear.

It is still a challenge to distinguish the effects of long-term climate change from those of short-term environmental fluctuations on $\mathrm{C}$ cycle. Large uncertainty exists in present measurements of $\mathrm{C}$ input and output of ecosystem, and in detecting the variation in soil C stocks [10]. Because of the high spatial heterogeneity in soil respiration and soil $\mathrm{C}$ density, it is difficult to accurately measure the average soil respiration rate and to detect a small variation in soil $\mathrm{C}$ stocks. Despite that data uncertainty is unlikely to change the conclusion of these three papers that $\mathrm{C}$ stocks in northern China's grasslands were relatively stable, the impacts of uncertainty on understanding ecosystem $\mathrm{C}$ cycling and underlying mechanisms and estimating the strength of $\mathrm{C}$ sink or source still limit the conclusions that can be drawn. Estimated $R / S$ ratio varied among different sampling methods [2,3]. At a regional scale, the NDVI index from remote sensing is an effective approach to estimate above-ground biomass $[3,4]$. However, there is a large uncertainty in the estimate it provides, due to the lack of historical data from ground measurement for calibration. Furthermore, in respect to the great soil $\mathrm{C}$ stocks and a high spatial heterogeneity in the region, two decades of data may not be long enough to reliably assess ecosystem response to long-term climate change at the regional scale, given that there was no significant variation in the balance between $\mathrm{C}$ input and output of ecosystems. This decreases the degree of confidence that can be placed in any prediction.

Research should aim to improve the understanding of the mechanisms of $\mathrm{C}$ stabilization in northern China's grasslands and to reliably predict the possible future changes in these ecosystems. This could be achieved with study objectives of: (i) separating the effects of short-term environmental fluctuation and long-term climate change by jointly using ecosystem process models and pattern analysis of the variation in productivity and $\mathrm{C}$ stocks at a large scale; (ii) investigating the key mechanisms controlling ecosystem productivity and soil organic $\mathrm{C}$ decomposition in northern China's grasslands through long-term field measurements and experiments; and (iii) the development of new techniques for detecting the variation in soil $\mathrm{C}$ stocks, data fusion and uncertainty analysis when scaling from small-scale to region-level estimates.

In near future, great uncertainty may still exist in assessing the feed-backs between terrestrial ecosystem $\mathrm{C}$ cycling and global climate change [7]. A relatively stable $\mathrm{C}$ stock in response to climate change in northern China's grasslands does not only affect the regional assessment of $\mathrm{C}$ balance, knowledge of underlying mechanisms causing this stability would also help toward understanding the feedback between global $\mathrm{C}$ cycling and climate change.

1 Heimann M, Reichstein M. Terrestrial ecosystem carbon dynamics and climate feedbacks. Nature, 2008, 451: 289-292

2 Wang L, Niu K C, Yang Y H, et al. Patterns of above- and belowground biomass allocation in China's grasslands: evidence from individual-level observations. Sci China Life Sci, 2010, 53: 851857

3 Ma W H, Fang J Y, Yang Y H, et al. Biomass carbon stocks and their changes in northern China's grasslands during 1982-2006. Sci China Life Sci, 2010, 53: 841-850

4 Fang J Y, Yang Y H, Ma W H, et al. Ecosystem carbon stocks and 
their changes in China's grasslands. Sci China Life Sci, 2010, 53: 757-765

5 Yang Y, Fang J, Smith P, et al. Changes in topsoil carbon stock in the Tibetan grasslands between the 1980s and 2004. Glob Change Biol, 2009, 15: 2723-2729

6 Yang Y H, Fang J Y, Ma W H, et al. Soil carbon stock and its changes in northern China's grasslands from 1980s to 2000s. Glob Change Biol, 2010, 16: 3036-3047

7 Bond-Lamberty B, Thomson A. Temperature-associated increases in the global soil respiration record. Nature, 2010, 464: 579-583
8 Ma W H, Liu Z L, Wang Z H, et al. Climate change alters interannual variation of grassland aboveground productivity: evidence from a 22-year measurement series in the Inner Mongolian grassland. J Plant Res, 2010, 123: 509-517

9 Bai W, Wan S, Niu S, et al. Increased temperature and precipitation interact to affect root production, mortality, and turnover in a temperate steppe: implications for ecosystem $\mathrm{C}$ cycling. Glob Change Biol, 2010, 16: 1306-1316

10 Smith P, Fang C. A warm response by soils. Nature, 2010, 464: 499-500

Open Access This article is distributed under the terms of the Creative Commons Attribution License which permits any use, distribution, and reproduction in any medium, provided the original author(s) and source are credited. 